\title{
Sicherer Halt an der Grenze des Chargenmaßes
}

\author{
Für die zuverlässige Reinigung eines neu entwickelten Resonators für ein Lasergerät muss das Bauteil \\ rotiert werden. Dies macht einen Werkstückträger erforderlich, der sicheren Halt bietet, aber gleichzeitig \\ die Außenabmessungen nicht vergrößert. Die Lösung liegt in einer Sonderkonstruktion, die ohne
}

Außenrahmen auskommt.

$D^{c}$ er neu entwickelte Resonator dient als Grundträger, an dem die verschiedenen Bauteile eines Lasergeräts befestigt werden. Das Bauteil wird im Aluminium-Druckguss gefertigt und spanend bearbeitet. Bei einer Neukonstruktion wurden in den Grundträger weitere Funktionen integriert, wie beispielsweise die Kühlung. Er hat, mit Vertiefungen für das Kühlmedium, nicht nur eine deutlich komplexere Geometrie als das Vorgängermodell, es müssen auch höhere Sauberkeitsanforderungen erfüllt werden.

So ist während des Reinigungsund Trocknungsprozesses eine Rotationsbewegung erforderlich. Dies wiederum macht einen verdeckelbaren Werkstückträger notwendig, der das Teil sicher in Position hält. Eigentlich stellt dies kein Problem dar, würden die Abmessungen des rund 50 Kilogramm schweren Bauteils nicht schon bis auf weni-

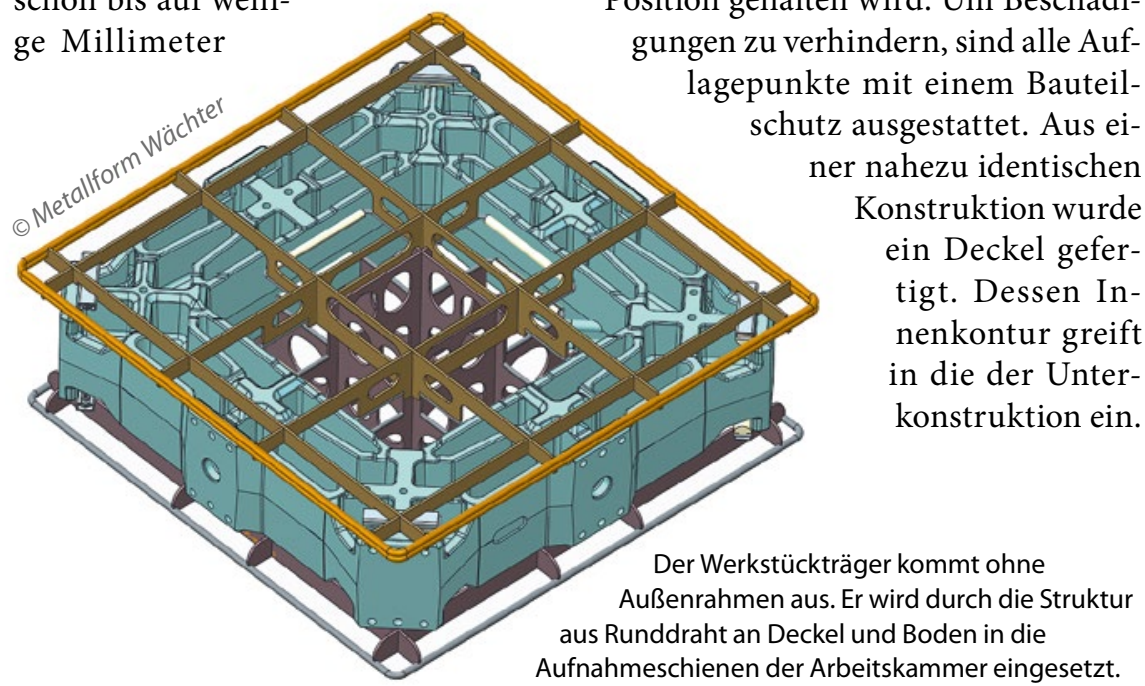

am Chargenmaß der Reinigungsanlage liegen.

\section{Sicherer Halt durch außen offene Konstruktion}

Das hohe Teilegewicht und der Platzmangel in der Arbeitskammer stellten bei der Entwicklung eines bedarfsgerechten Werkstückträgers eine Herausforderung dar. Die Lösung lag in einer individuell angepassten Sonderkonstruktion von Metallform Wächter. Sie besteht aus auswechselbaren, ineinander gesteckten C-Schienen, die das hohe Gewicht aufnehmen können, ohne dass sie auf Dauer beschädigt werden.

Auf diesem Rahmen, der genau der Länge und Breite des Resonators entspricht, liegt das Bauteil auf. In der Mitte verläuft die Kontur des Werkstückträgers in Höhe des Resonators tetragonal nach oben, wodurch er in Position gehalten wird. Um Beschädigungen zu verhindern, sind alle Aufschutz ausgestatet. Aus eir nahezu identischen Konstruktion wurde ein Deckel gefertigt. Dessen Innenkontur greift in die der Unterkonstruktion ein.
Schnelle und zuverlässige Trocknung

Boden und Deckel sind darüber hinaus mit einer umlaufenden Struktur aus Runddraht ausgestattet. Sie wird in die Aufnahmeschienen der Arbeitskammer eingeschoben, die mit rotieren und die beiden Teile während des Reinigungsprozesses zusammenhalten. Der rohrförmige, horizontal angebrachte Bauteileschutz an der Innenkontur ermöglicht eine Rollwirkung, die das Einsetzen und Entnehmen des beladenen Reinigungsbehältnisses erleichtert. Die speziell angepasste Lösung bietet einerseits den beim Rotieren erforderlichen Halt. Andererseits sorgt die offene Konstruktion dafür, dass das Reinigungsmedium und die Waschmechanik ungehindert zum Bauteil gelangen und die Trocknung schnell erfolgt.

Gefertigt werden die Werkstückträger - wie alle Reinigungsbehältnisse von Metallform - aus rostfreiem Edelstahl mit elektropolierter Oberfläche. Das hochwertige Material kann mit allen Reinigungsmedien eingesetzt werden und ermöglicht eine lange Nutzungsdauer der Behältnisse. Die Rundstäbe der äußeren Struktur sind stumpf verschweißt, wodurch verletzungsgefährliche Ecken vermieden werden. I

\section{Kontakt:}

Metallform Wächter GmbH, Bretten,

Tel. 07252942610 ,

anja.waechter@metallform.de,

www.metallform.de 